\title{
STATISTICAL AND NUMERICAL INVESTIGATION OF GAS/LIQUID FLOW IN THE NEAR WELLBORE REGION
}

\author{
Ekhwaiter Abobaker ${ }^{1}$, Abadelhalim Elasnoose ${ }^{1}$, Mohammad Azizur Rahman ${ }^{2}$, John Shirokoff ${ }^{1}$, \\ Amer Aborig ${ }^{1}$, Mohammad Jalal Ahammad ${ }^{1}$ \\ ${ }^{1}$ Memorial University of Newfoundland, Canada \\ ${ }^{2}$ Texas A\&M University at Qatar, Doha, Qatar
}

\begin{abstract}
Horizontal wells are considered a relatively advanced method of drilling that maximize the reservoir productivity index because of having higher contact area between the formation and the wellbore. The reservoir productivity index relies on the properties of the reservoir flow, which itself is highly dependent on wellbore geometry, completion technique, and specific reservoir parameters. Multiphase flow model through horizontal near-wellbore region has been conducted to analyze the effects of skin zone diameter (damaged region) and the influence of perforation distribution on enhanced oil recovery. Statistical analysis was coupled with numerical simulation in order to expand the investigation on fluid flow at near wellbore region. The statistical analysis is used to investigate the effect of several parameters such as, the skin zone diameter penetration space, angle and depth as well as the perforation diameter on the injection build-up pressure and the time needed for reaching steady-state flow condition. Design Expert Software (DoE) version 11 package has been used to determine the numerical simulation runs using the ANOVA analysis with Box-Behnken Design "BBD" model. Forty-one numerical runs have been generated using DoE to achieve the whole statistical analysis. ANSYS-Fluent software 18.1 has been used to carry out the numerical simulation in the porous media tunnel by applying the volume of fluid method (VOF). The numerical and statistical analysis showed a clear view of the effect of each investigated parameter on the injection build-up pressure and time required for reaching the steady-state. In addition, two correlations have been obtained from the statistical analysis and numerical simulation in which can be used to predict the injection build-up pressure and the required time to reach steady state for different scenarios. This study will be very helpful in choosing the optimal perforation distribution and understanding the multiphase flow behavior in horizontal near wellbore region.
\end{abstract}

KEY WORDS: statistical, numerical, two phase flow, near wellbore region, CFD.

\section{INTRODUCTION}

Horizontal wells, which are commonly used as a means for extracting oil and gas, are considered a relatively advanced method of drilling. This type of well is recently common during the reservoir development stage, given the positioning of its high area connecting the formation with the wellbore. In general, a horizontal well's productivity relies on the properties of the reservoir flow, which itself is highly dependent on wellbore geometry, completion technique, and specific reservoir parameters. Extraction of well fluid from a formation requires a perforation of the formation inside the horizontal wellbore. As illustrated by Fig. 1, such a perforation enables fluid communication to take place between the wellbore and the reservoir. A perforated well's productivity depends on a number of different factors that interact with each other, such as penetration space, angle, depth as well as perforation diameter. 2For our purposes, a well's productivity index can be defined by the rate of flow (moving from the bottom upwards) that corresponds to the level of pressure energy that needs to be consumed to perform the task. Pressure drops are impacted through perforation parameter configurations and can have a significant effect on the productivity index. 
The literature shows that several researchers have studied how perforation parameters can impact a perforated well's productivity. For example, in [1], Landman and Goldthorpe presented a mathematical model for describing perforation distribution effects on a perforated horizontal well's performance under conditions of steady, single-phase flow. In Landman and Goldthorpe's [1] model, the darcy flow was applied to individual perforations using a one-dimensional momentum equation as pipe flow and any pressure drops were due solely to wall friction. Similarly, in [2], Asheim et al. proposed used a friction factor correlation for determining a more accurate friction factor caused by wall friction in conjunction with fluid flow from perforation. In other work, Locke [3] proposed a theoretical approach for determining a perforated vertical wellbore's productivity ratio, developing a simulation model that was more accurate than previous methods due to the much finer finite element method used by the researcher for running the simulations.

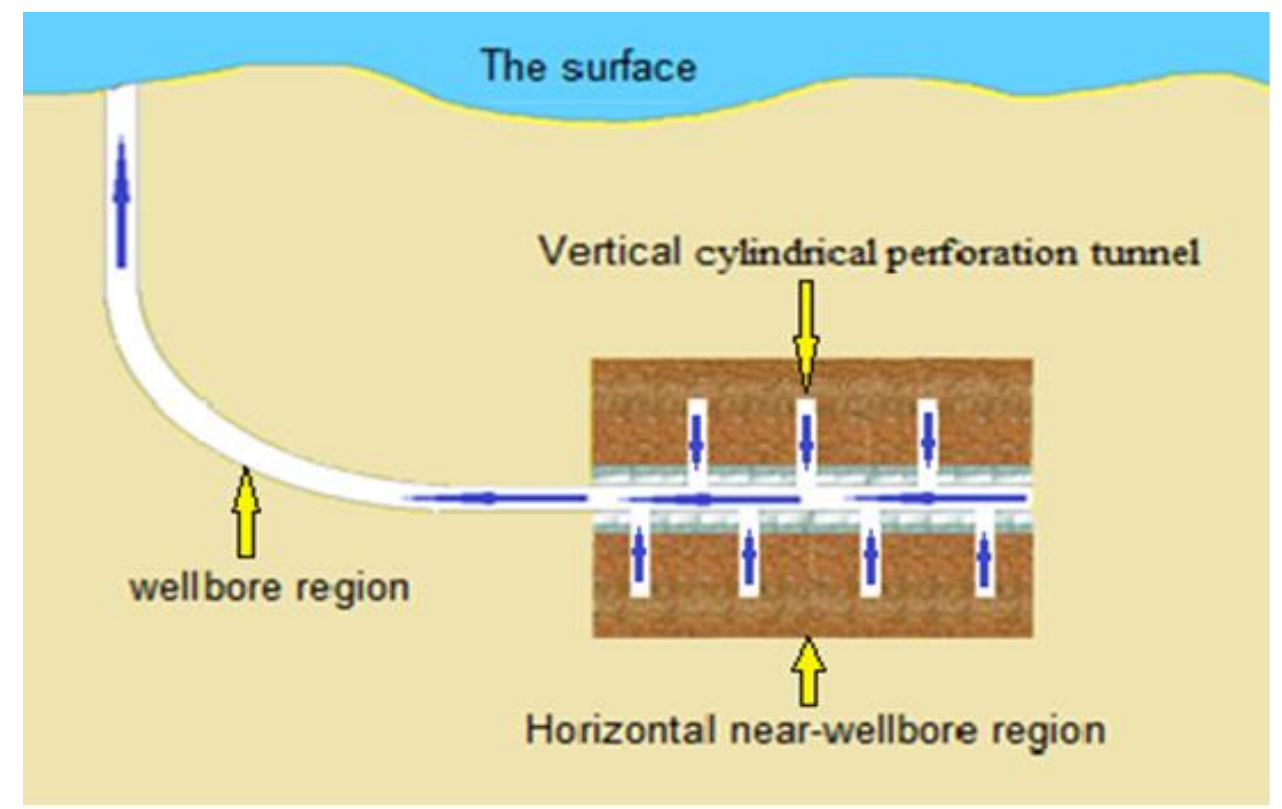

Fig. 1 Schematic of the horizontal near-wellbore region and vertical cylindrical perforation tunnel

Pressure drop can take a number of forms, the main ones being friction, gravity, mixing and acceleration. In [4], Su and Gudmundsson explored the mixing of fluids between the main flow and the inflow, looking to see how these four factors (friction, gravity, mixing and acceleration) can affect a perforated horizontal wellbore. Schulkes and Utvik [5] also looked at pressure drop in perforated horizontal pipelines, although their work focused on pipes that featured extensive perforations. Using experimental measurements, the researchers studied how inflow impacted pressure drop in relation to both mixing and acceleration, discovering mixing pressure drop to be approximately $10 \%$ of friction pressure drop. In the same line of research, Li et al. [6] investigated total pressure drop for two-phase liquid and gas using the three factors of mixing, acceleration and friction. The outcome of their tests indicated that the pressure drop for mixing and acceleration comprises less than one-seventh (approx. 15\%) of total pressure drop, whereas the pressure drop for friction exceeds $85 \%$ of total pressure drop.

Rahman et al. [7-10] in 2006-2008, investigated perforation in single-phase flow through comparing a drilling method to perforation with a shooting technique. Rahman et al, also looked at how the skin effect impacts the permeability of near wellbore under these techniques. The researchers discovered that during the shooting method, there was a redistribution of fine particles throughout the perforation tunnel. In another study on perforation, Yildiz [11] presented a three-dimensional analytical model for determining a vertical well's productivity ratio. The model included aspects such as different phase angles, diameters and lengths of perforations, as well as formation damage which occurs in the area of the perforations. Ansah et al. [12] also proposed a three-dimensional model for a vertical wellbore. This model was developed to explore the impacts of perforation phase angle, phase length, pipe diameter and shot density on well productivity. In their work, 
the researchers employed a three-dimensional finite element model in order to demonstrate potential enhancements to inflow [12]. In [13], Dogulu constructed a numerical model for gauging productivity in a variety of different wells (horizontal, vertical, slanted, and perforated), looking specifically at the effects of perforation density, penetration depth and penetration angle. Dogulu [13] applied a finite-difference approach for the single-phase flow and constructed the perforated well grid using an algebraic grid generation method. In [14], Hagoort proposed an analytical model for measuring a perforated vertical wellbore's productivity ratio, using the analytical solution from a darcy flow in a single perforation and single-phase flow. Recently, Zheng et al. $[15,16]$ numerically simulated and experimentally investigated two-phase fluid flows occurring in perforated porous substances. The researchers' model was able to predict pressure gradients of petrophysical characteristics within perforation tunnels.

In other related work, Zeboudj et al. [17] investigated total pressure drop caused by acceleration and friction occurring at the perforated horizontal wellbore. The researchers focused on single-phase steady flows and employed CFD simulation derived from FLUENT for their calculations. Finally, Dankwa and Igbokoyi [18] adopted an analytical approach to determine the productivity index in vertical wells at partial completion. These two researchers [18] also measured the impact of pressure drop by applying a pressure drop equation for partial completion.

Due to the importance of the subject and its strong impact on productively index, several numerical and analytical calculations have been presented to determine how perforation parameters impact the main flow's efficiency levels. In the present work, the numerical simulation and statistical analysis of variance (ANOVA) is applied to analyze the effects of skin zone diameter (damaged region) and parameters of perforation in a horizontal near-wellbore region on the injection build-up pressure. The study also looks at the time required for reaching the steady-state and how these parameters interact with each other in two-phase flow in the horizontal near-wellbore region through different dimensions and distributions of the perforation at the same flow boundary conditions

\section{METHODOLOGY}

\section{1. Numerical simulation procedure.}

Mathematical model. The physical velocity porous formulation used to solve and simulate the multiphase flows in the porous media tunnel. The definition of velocity in multiphase flow modeling is presented by using two different characterizations: Physical and superficial velocity formulation. Physical velocity formulation take the porosity into calculation through the valuation of the continuity, momentum equations, unlike superficial velocity that doesn't take it into computation. ANSYS-Fluent 18.1 calculates the multiphase flow in a porous region based on the volumetric flow rate. In this way, the governing equation in a porous media takes the form as follows [19]:

$$
\frac{\partial\left(\gamma \alpha_{q} \rho_{q} \emptyset_{q}\right)}{\partial t}+\nabla \cdot\left(\gamma \alpha_{q} \rho_{q} \vec{v}_{q} \emptyset_{q}\right)=\nabla \cdot\left(\gamma \Gamma_{q} \nabla \emptyset_{q}\right)+\gamma S_{\emptyset, q}
$$

Assuming isotropic porosity and multiphase flow, the continuity and momentum equation for two-phase flow through a porous region can be written as [19]:

The continuity equation:

$\frac{\partial}{\partial t}\left(\gamma \alpha_{q} \rho_{q}\right)+\nabla \cdot\left(\gamma \alpha_{q} \rho_{q} \vec{v}_{q}\right)=\gamma \sum_{p=1}^{n}\left(\dot{m}_{p q}-\dot{m}_{q p}\right)+\gamma S_{q}$ 
The momentum equation:

$$
\begin{array}{ll}
\left(\gamma \alpha_{q} \rho_{q} \vec{v}_{q}\right)+\nabla \cdot\left(\gamma \alpha_{q} \rho_{q} \vec{v}_{q} \vec{v}_{q}\right)=-\gamma \alpha_{q} \nabla_{\left(p-p_{c}\right)}+\nabla \cdot\left(\gamma \overline{\bar{\tau}}_{q}\right)+\gamma \alpha_{q} \rho_{q} \vec{B}_{f}-\left(\alpha_{q}^{2} \gamma^{2} \frac{\mu_{q} \vec{v}_{q}}{K K_{r, q}}+\right. \\
\left.\alpha_{q}^{3} \gamma^{3} \frac{C_{2 \rho}\left|\vec{v}_{q}\right| \vec{v}_{q}}{2}\right)+ & \gamma \sum_{p=1}^{n}\left(\vec{F}_{p q}^{D}+\vec{F}_{p q}^{T D}+\dot{m}_{p q} \vec{v}_{p q}-\dot{m}_{q p} \vec{v}_{q p}\right)+ \\
\gamma\left(\vec{F}_{q}+\vec{F}_{q}^{L}+\vec{F}_{q}^{v m}\right) &
\end{array}
$$

Computational technique. ANSYS fluent is a high performance simulation tool that has been used to solve wide-ranging fluid flow problems with reliable and accurate solutions. ANSYS-Fluent 18.1 (3D) simulates the multiphase flow in the horizontal cylindrical near-wellbore region in the three different skin zone diameters (damaged region) and different perforation density as shown in Fig. 2. For the multiphase flow model, the volume of fluid method coupled with k- $\varepsilon$ turbulence model has applied to solve the air-water flow in the porous media. The volume of fluid method (VOF) is designed for immiscible fluids where it has the ability to predict the situation of the interface between the immiscible fluids during the flow time. In the computational fluid dynamics field, the $\mathrm{k}-\varepsilon$ turbulence model is the most common turbulent model used. The outer side of the cylindrical skin zone is considered as an inlet while the perforations and wellbore surface taken as an outlet. The numerical procedure is carried out at the same flow boundary conditions are listed in table (1).

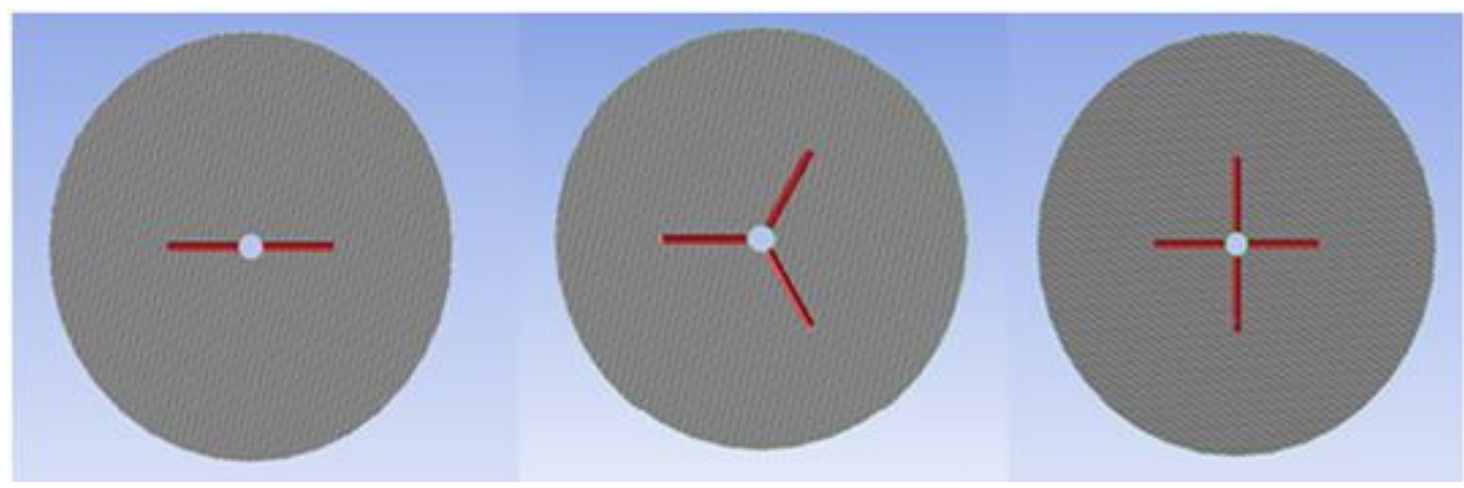

Fig. 2 Three penetration angle $\left(180^{\circ}, 120^{\circ}\right.$ and $\left.90^{\circ}\right)$ that used in CFD simulations of two-phase.

Table 1 The flow boundary conditions.

\begin{tabular}{c|c|c}
\hline Flow Boundary conditions & Values & Flow Boundary conditions \\
\hline Water mass flow rate & 0.32 & $\mathrm{~kg} / \mathrm{s}$ \\
Air mass flow rate & 0.00067375 & $\mathrm{~kg} / \mathrm{s}$ \\
Permeability & 0.034 & Darcy \\
Porosity & 15 & $\%$ \\
Water viscosity & 0.0011 & $\mathrm{~kg} / \mathrm{m} . \mathrm{s}$ \\
Density of water & 998.2 & $\mathrm{Kg} / \mathrm{m}^{3}$ \\
Air viscosity & $1.7894 \mathrm{e}-05$ & $\mathrm{~kg} / \mathrm{m} . \mathrm{s}$ \\
Pressure outlet & Atmospheric pressure & $\mathrm{Pa}$ \\
\hline
\end{tabular}


Uniform mesh and cut mesh method have been used to generate the high quality mesh as shown in Fig. 3 . This configuration helped to predict a good quality and high density mesh close to perforation borders.

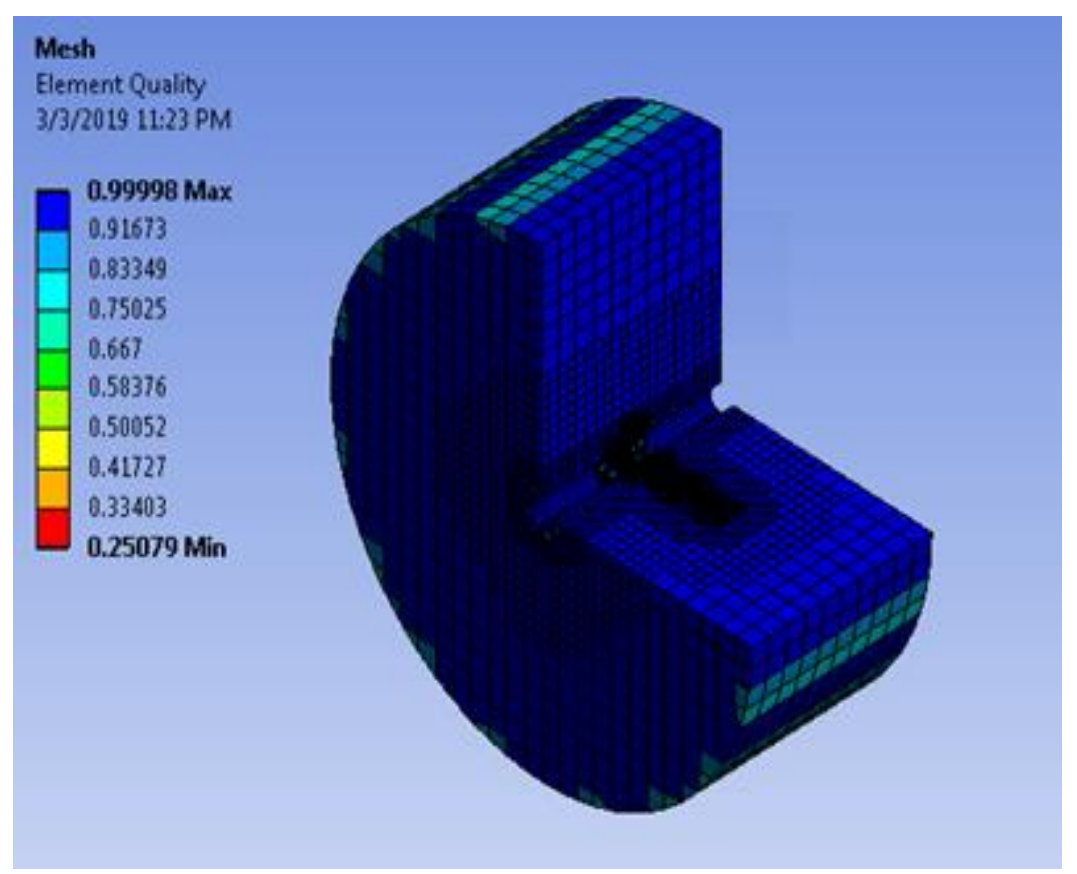

Fig. 3 3D view of configuration mesh for horizontal wellbore region and mesh quality (case. 28).

\section{2. Statistical analysis procedure}

Design of Experiments (DoE) refers to several different strategies that determine how various parameters can help alter results in controlled experiments. In these strategies, the first step identifies any independent factors or variables which can impact the outcome, followed by the identification of dependent factors or variables. Typically, these experiments run according to a variety of levels or factor values. Every experimental run represents a different combination of specific levels (or factor values) under investigation. The Box-Behnken design (BBD), which is a response surface methodology (RSM) design, only needs three levels for experimental runs. For the proposed study, Design Expert software with BBD is used to design the needed runs for the statistical analysis, with the model being statistically validated using analysis of variance (ANOVA).

Table 2 The range dimensions of the near-wellbore geometry and perforation density.

\begin{tabular}{c|c|c}
\hline Boundary conditions & Range & Units \\
\hline Skin zone diameter & 120,140 and 160 & $\mathrm{~cm}$ \\
Penetration Space & 1,2 and 3 & $(-)$ \\
Penetration Angle & 2,3 and 4 & $180^{\circ}, 120^{\circ}$ and $90^{\circ}$ \\
Penetration Depth & 15,25 and 35 & $\mathrm{~cm}$ \\
Perforation Diameter & $1.5,2.5$ and 3.5 & $\mathrm{~cm}$ \\
Wellbore Diameter & 8 & $\mathrm{~cm}$ \\
Near-Wellbore length & 60 & $\mathrm{~cm}$ \\
\hline
\end{tabular}


Based on these initial processes, the main important parameters were investigated including the skin zone diameter, penetration space, angle, depth, and the perforation diameter. Two boundary points are then selected, and one midpoint is chosen by BBD for the intervals of the parameters, as presented in table (2). Forty-one numerical runs are performed and analyzed to obtain a suitable statistical analysis using the ANOVA analysis with BBD model, as shown in table (3). Note that the last two column in table (3) show the results of the injection build-up pressure and the build-up pressure steady-state time that obtained from the numerical analysis.

Table 3 The Design Expert software numerical run design and results.

\begin{tabular}{|c|c|c|c|c|c|c|c|}
\hline $\begin{array}{l}\text { Run } \\
\text { No }\end{array}$ & $\begin{array}{l}\text { Skin zone } \\
\text { diameter } \\
\text { SZD }(\mathrm{cm})\end{array}$ & $\begin{array}{l}\text { Penetration } \\
\text { Space PS (-) }\end{array}$ & $\begin{array}{l}\text { Penetration Angle } \\
\text { PA }\left(90^{\circ}-180^{\circ}\right)\end{array}$ & $\begin{array}{l}\text { Penetration } \\
\text { Depth } \mathrm{P}_{\mathrm{d}} \\
(\mathrm{cm})\end{array}$ & $\begin{array}{l}\text { Perforation } \\
\text { Diameter } \\
\text { PD }(\mathrm{cm})\end{array}$ & $\begin{array}{l}\text { Pressure } \\
(\mathrm{Pa})\end{array}$ & $\begin{array}{c}\text { Time } \\
\text { (s) }\end{array}$ \\
\hline 1 & 120 & 1 & $\left(360^{\circ} / 120^{\circ}\right)=3$ & 25 & 2.5 & $5.54 \mathrm{E}+06$ & 118 \\
\hline 2 & 140 & 2 & $\left(360^{\circ} / 180^{\circ}\right)=2$ & 15 & 2.5 & $6.59 \mathrm{E}+06$ & 156 \\
\hline 3 & 140 & 3 & $\left(360^{\circ} / 120^{\circ}\right)=3$ & 15 & 2.5 & $5.8 \mathrm{E}+06$ & 159 \\
\hline 4 & 140 & 2 & $\left(360^{\circ} / 120^{\circ}\right)=3$ & 35 & 1.5 & $4.45 \mathrm{E}+06$ & 171 \\
\hline 5 & 120 & 2 & $\left(360^{\circ} / 180^{\circ}\right)=3$ & 25 & 2.5 & $5.38 \mathrm{E}+06$ & 119 \\
\hline 6 & 160 & 2 & $\left(360^{\circ} / 120^{\circ}\right)=3$ & 25 & 1.5 & $5.6 \mathrm{E}+06$ & 210 \\
\hline 7 & 160 & 2 & $\left(360^{\circ} / 120^{\circ}\right)=3$ & 15 & 2.5 & $6.64 \mathrm{E}+06$ & 205 \\
\hline 8 & 160 & 2 & $\left(360^{\circ} / 120^{\circ}\right)=3$ & 25 & 3.5 & $5.077 \mathrm{E}+06$ & 212 \\
\hline 9 & 140 & 1 & $\left(360^{\circ} / 90^{\circ}\right)=4$ & 25 & 2.5 & $5.573 \mathrm{E}+06$ & 163 \\
\hline 10 & 140 & 2 & $\left(360^{\circ} / 120^{\circ}\right)=3$ & 35 & 3.5 & $3.887 \mathrm{E}+06$ & 175 \\
\hline 11 & 140 & 3 & $\left(360^{\circ} / 120^{\circ}\right) 3$ & 25 & 1.5 & $4.7 \mathrm{E}+06$ & 165 \\
\hline 12 & 140 & 3 & $\left(360^{\circ} / 180^{\circ}\right)=2$ & 25 & 2.5 & $5.2 \mathrm{E}+06$ & 160 \\
\hline 13 & 160 & 3 & $\left(360^{\circ} / 120^{\circ}\right)=3$ & 25 & 2.5 & $4.902 E+06$ & 215 \\
\hline 14 & 140 & 2 & $\left(360^{\circ} / 180^{\circ}\right)=2$ & 25 & 1.5 & $5.818 \mathrm{E}+06$ & 158 \\
\hline 15 & 140 & 2 & $\left(360^{\circ} / 180^{\circ}\right)=2$ & 35 & 2.5 & $4.908 \mathrm{E}+06$ & 163 \\
\hline 16 & 140 & 1 & $\left(360^{\circ} / 120^{\circ}\right)=3$ & 35 & 2.5 & $5.033 \mathrm{E}+06$ & 166 \\
\hline 17 & 140 & 1 & $\left(360^{\circ} / 120^{\circ}\right)=3$ & 25 & 1.5 & $6.229 \mathrm{E}+06$ & 158 \\
\hline 18 & 160 & 2 & $\left(360^{\circ} / 120^{\circ}\right)=3$ & 35 & 2.5 & $4.439 \mathrm{E}+06$ & 222 \\
\hline 19 & 140 & 2 & $\left(360^{\circ} / 120^{\circ}\right)=3$ & 15 & 1.5 & $6.474 \mathrm{E}+06$ & 156 \\
\hline 20 & 120 & 2 & $\left(360^{\circ} / 90^{\circ}\right)=4$ & 25 & 2.5 & $4.164 \mathrm{E}+06$ & 128 \\
\hline
\end{tabular}




\begin{tabular}{|c|c|c|c|c|c|c|c|}
\hline 21 & 140 & 1 & $\left(360^{\circ} / 120^{\circ}\right)=3$ & 25 & 3.5 & $5.733 \mathrm{E}+06$ & 159 \\
\hline 22 & 160 & 2 & $\left(360^{\circ} / 180^{\circ}\right)=2$ & 25 & 2.5 & $5.895 \mathrm{E}+06$ & 206 \\
\hline 23 & 140 & 1 & $\left(360^{\circ} / 120^{\circ}\right)=3$ & 15 & 2.5 & $7 E+06$ & 158 \\
\hline 24 & 120 & 2 & $\left(360^{\circ} / 120^{\circ}\right)=3$ & 35 & 2.5 & $3.746 \mathrm{E}+06$ & 132 \\
\hline 25 & 140 & 3 & $\left(360^{\circ} / 90^{\circ}\right)=4$ & 25 & 2.5 & $4.154 \mathrm{E}+06$ & 175 \\
\hline 26 & 140 & 2 & $\left(360^{\circ} / 120^{\circ}\right)=3$ & 25 & 2.5 & $5 E+06$ & 163 \\
\hline 27 & 140 & 2 & $\left(360^{\circ} / 120^{\circ}\right)=3$ & 15 & 3.5 & $6.039 \mathrm{E}+06$ & 157 \\
\hline 28 & 140 & 1 & $\left(360^{\circ} / 180^{\circ}\right)=2$ & 25 & 2.5 & $6.471 \mathrm{E}+06$ & 157 \\
\hline 29 & 120 & 2 & $\left(360^{\circ} / 120^{\circ}\right)=3$ & 25 & 1.5 & $4.934 \mathrm{E}+06$ & 121 \\
\hline 30 & 140 & 3 & $\left(360^{\circ} / 120^{\circ}\right)=3$ & 35 & 2.5 & $3.665 \mathrm{E}+06$ & 177 \\
\hline 31 & 140 & 2 & $\left(360^{\circ} / 90^{\circ}\right)=4$ & 35 & 2.5 & $3.619 \mathrm{E}+06$ & 182 \\
\hline 32 & 140 & 3 & $\left(360^{\circ} / 120^{\circ}\right)=3$ & 25 & 3.5 & $4.336 \mathrm{E}+06$ & 169 \\
\hline 33 & 160 & 1 & $\left(360^{\circ} / 120^{\circ}\right)=3$ & 25 & 2.5 & $6.226 \mathrm{E}+06$ & 207 \\
\hline 34 & 120 & 2 & $\left(360^{\circ} / 120^{\circ}\right)=3$ & 15 & 2.5 & $5.8 \mathrm{E}+06$ & 115 \\
\hline 35 & 140 & 2 & $\left(360^{\circ} / 180^{\circ}\right)=2$ & 25 & 3.5 & $5.473 \mathrm{E}+06$ & 159 \\
\hline 36 & 140 & 2 & $\left(360^{\circ} / 90^{\circ}\right)=4$ & 15 & 2.5 & $5.907 \mathrm{E}+06$ & 159 \\
\hline 37 & 160 & 2 & $\left(360^{\circ} / 90^{\circ}\right)=4$ & 25 & 2.5 & $4.928 \mathrm{E}+06$ & 214 \\
\hline 38 & 140 & 2 & $\left(360^{\circ} / 90^{\circ}\right)=4$ & 25 & 3.5 & $4.257 \mathrm{E}+06$ & 172 \\
\hline 39 & 120 & 3 & $\left(360^{\circ} / 120^{\circ}\right)=3$ & 25 & 2.5 & $4.106 \mathrm{E}+06$ & 124 \\
\hline
\end{tabular}

\section{RESULTS AND DISCUSSION}

The statistical analysis showed a clear view of the effect of each investigated parameter on the injection buildup pressure and time required for reaching the steady-state. For the design of experiments (DoE) model, the working assumptions were that: 1) numerical data has normal distribution and features constant variance; and 2) the presented and provided data are all independent from the other. In viewing the normal plot for residuals, we can see how the data points have been distributed along a line. Fig. 4 illustrates how the numerical data adheres to a normal distribution pattern for the two normal plot of residuals (the injection build-up pressure and the time required for reaching the steady-state). Moreover, the results point to the predicted model-derived values being nearly the same as the numerical-derived actual values. 


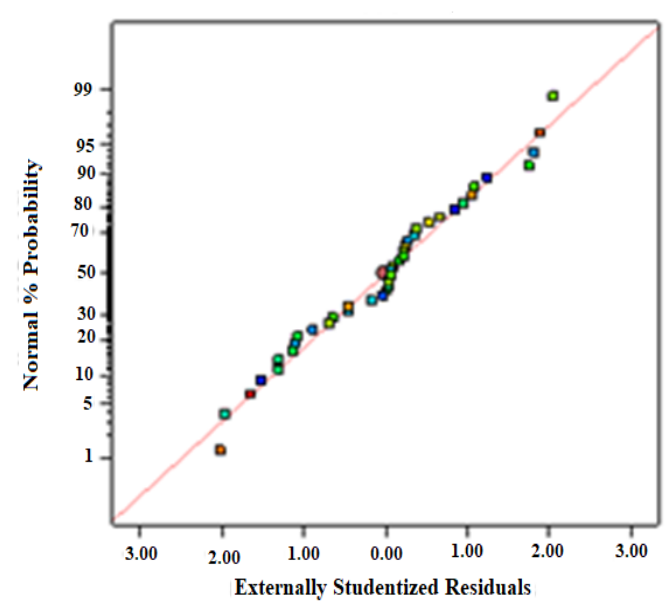

(A)

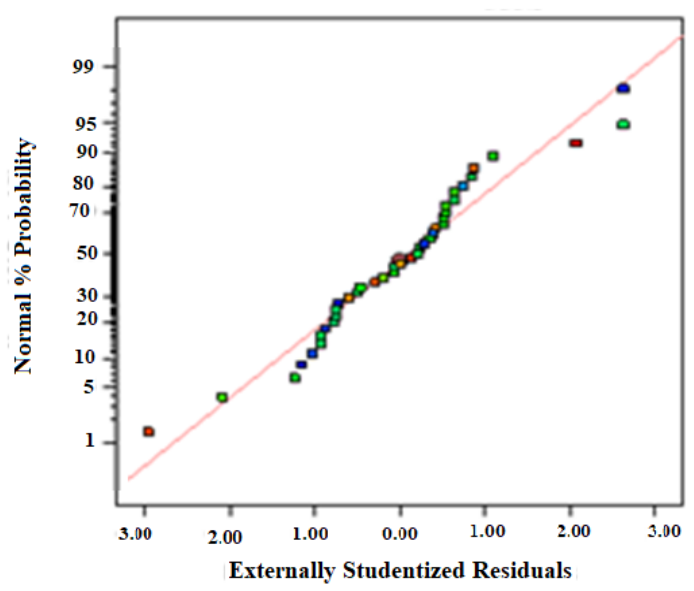

(B)

Fig. 4. Normal plot of residuals; (A) the injection build-up pressure; (B) the time required for reaching the steady-state.

The Box-Cox normality plot has been extensively used for DoE models in the literature. In the majority of statistical tests, there is an assumption of the sample's normality. In fact, this assumption of normality renders DoE testing quite powerful in comparison to testing that is not based on this assumption. In cases where samples do not satisfy the normality assumption, a data set transformation can be used in accordance with the Box-Cox plot. As shown in Fig. 5, in the Box-Cox plot for power transformation, lambda (1) is situated between the lambda confidence interval CI $(-0.6,2.6)$ for the injection build-up pressure and CI $(-0.25,2.25)$ for the time required for reaching the steady-state. Based on the ANOVA analysis, our design model shows a reasonable and desired outcome.

The design Expert software provided two correlations from the statistical analysis based on the numerical results. The two correlations can be used to predict the injection build-up pressure and the required time to reach steady state for different scenarios (the skin zone diameter and parameters of perforation) at the same flow boundary conditions.

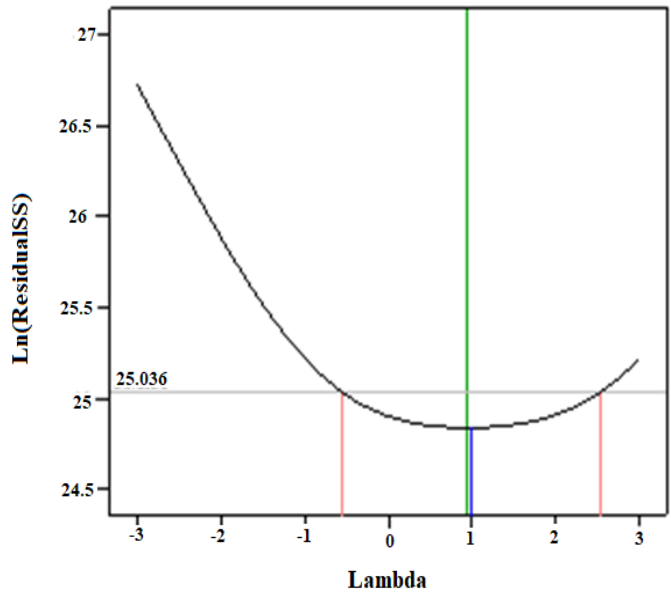

(A)

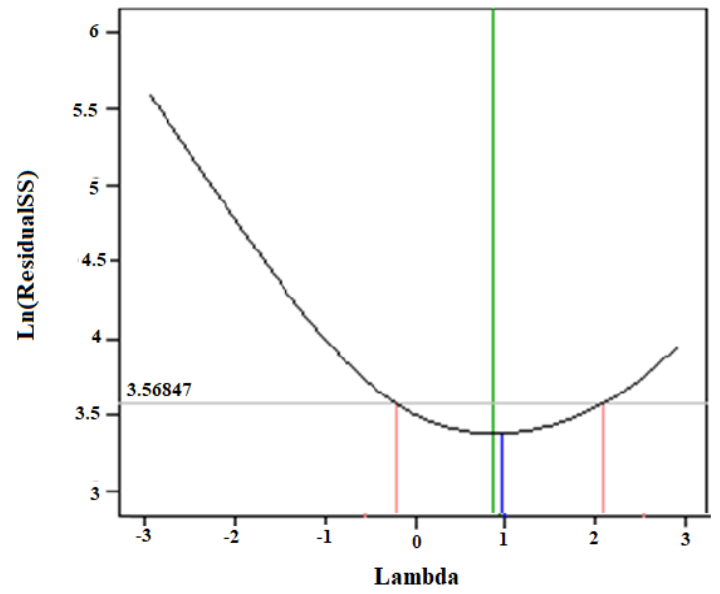

(B)

Fig. 5 Box-Cox plot for power transformations; (A) the injection build-up pressure; (B) the time required for reaching the steady-state. 
The first correlation predicts the injection build-up pressure for a given value of each investigated parameter (dimension), this correlation includes two constants (a and b). The second correlation predicts the required time to reach steady state, this correlation includes two constants ( $c$ and $d)$. The calculated $P$ and $t$ from the two correlations (4) and (5) are in a good agreement with the numerical results as shown in Figs 6, 7 under the same flow boundary conditions.

$$
\begin{aligned}
P(P a)= & 9.63661 E 6-1.63115 E 6 * P S-9.175 E 5 * P A-37000 * P S * P A+2.24458 E 5 * P S^{2}+ \\
& 1.00042 E 5 * P A^{2}+a *\left(S Z D-4.253 * P_{d}-7.11 * P D+0.06 * S Z D * P S+0.1285 * S Z D *\right. \\
& \left.P A-0.199 * P S * P_{d}+1.41935 * P S * P D-0.6516 * P A * P_{d}-2.8279 * P A * P D\right)- \\
& b *\left(S Z D * P_{d}-0.68 * S Z D * P D+17.415 * P_{d} * P D+0.2534 * S Z D^{2}-9.17 * P_{d}{ }^{2}-\right. \\
& \left.127.664 * P D^{2}\right)
\end{aligned}
$$

$$
\begin{aligned}
t(s)= & 64.11458-14.58333 * P S-14.06250 * P A+2.25 * P S * P A-0.041667 * P S^{2}+0.541667 * \\
& P A^{2}-c *\left(S Z D+16.728 * P_{d}+60.338 * P D-0.2033 * S Z D * P S+0.1017 * S Z D * P A-\right. \\
& \left.2.03389 * P S * P_{d}-6.1017 * P S * P D-3.254 * P A * P_{d}-10.17 * P A * P D\right)+d *(S Z D * \\
& \left.P D+6 * P_{d} * P D+0.6583 * S Z D^{2}+1.5 * P_{d}{ }^{2}-3.333 * P D^{2}\right)
\end{aligned}
$$

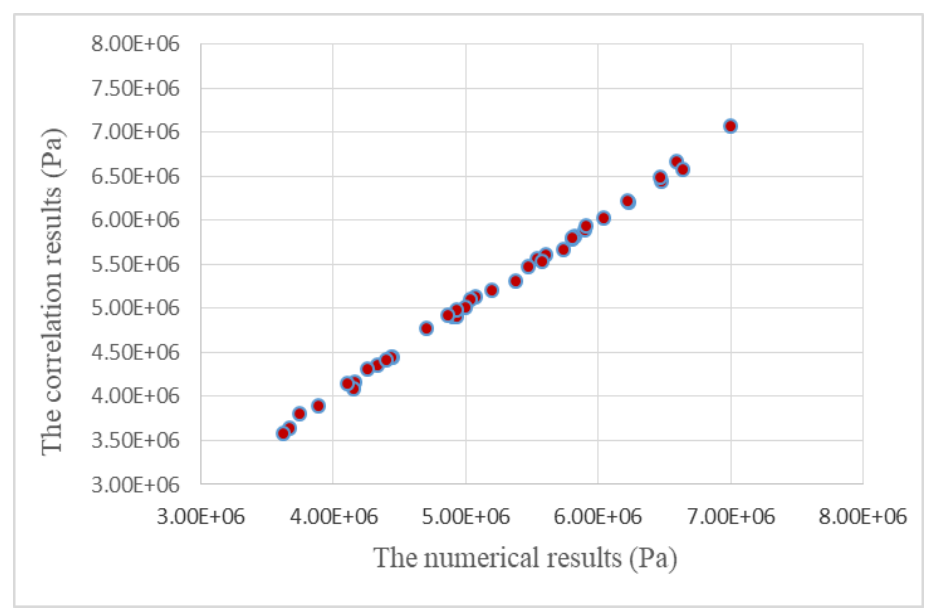

Fig. 6 Compression of numerical and correlation results for the injection build-up pressure (Pa).

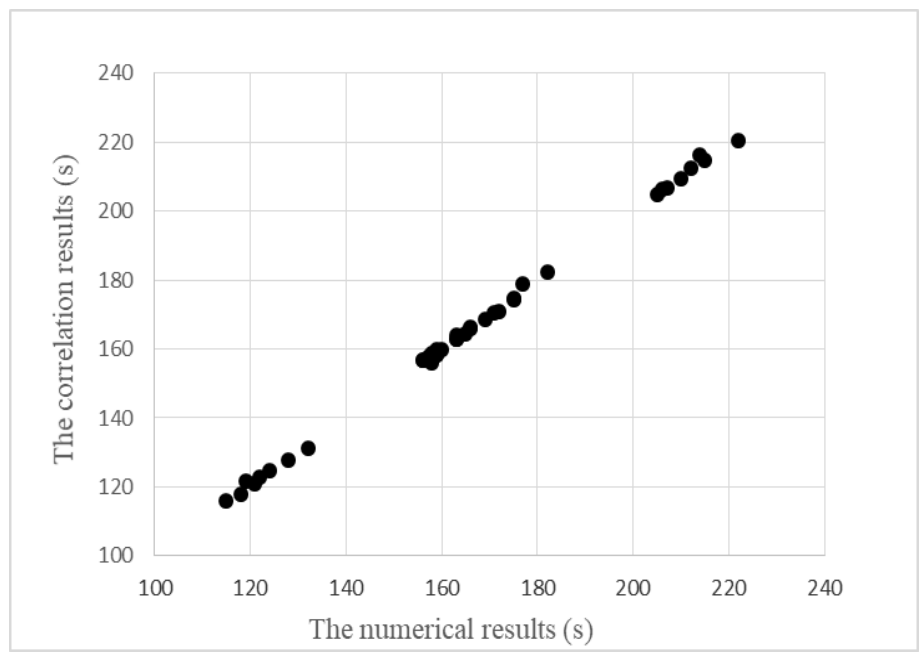

Fig. 7 Compression of numerical and correlation results for the required time to reach steady state (s). 
The study presented a thorough investigation of the effects of each perforation parameter on the injection build-up pressure as well as the time required for reaching the steady-state under the same flow boundary conditions. The results showed the specific effects of three different penetration angles on the injection buildup pressure gradient for the two-phase flow through the horizontal near wellbore region as shown in Fig 8 . The results indicated that the skin zone diameter (damaged region), the penetration depth and the penetration space have significant impacts on the injection build-up pressure, as shown in Fig .9 (A, B, C, E, G and L). Although skin zone diameter (damaged region) increases led to a rise in injection build-up pressure caused by higher resistance in larger skin zone diameter or damaged region, penetration depth increases led to a reduction in injection build-up pressure as a result of reduced resistance coupled with enhanced inflow rate. The higher inflow rate led to pressure energy consumption increases for accelerating the two-phase flow.

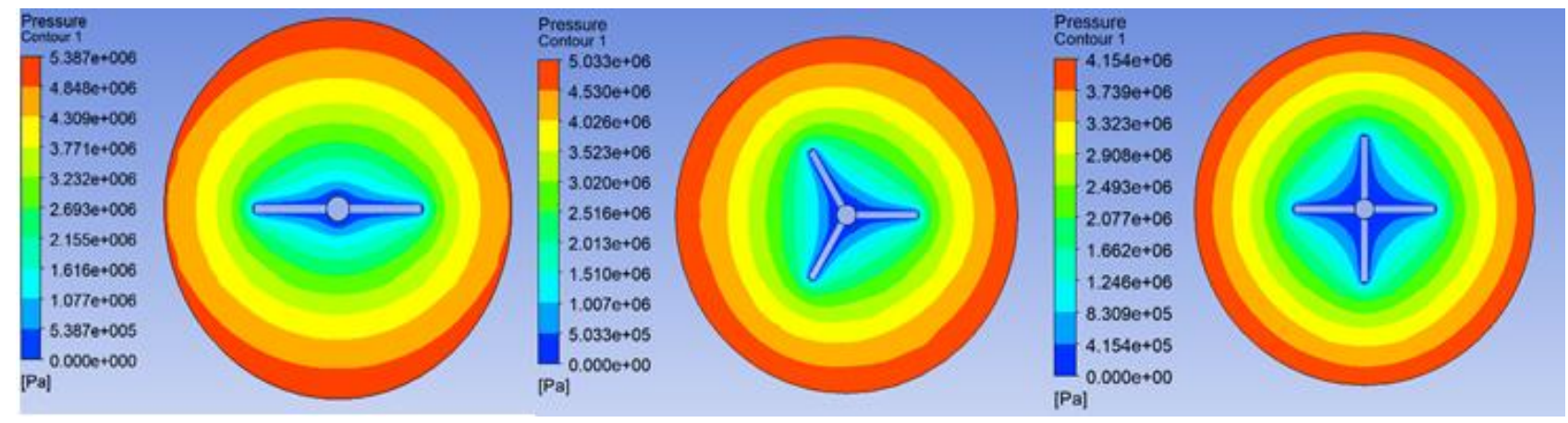

Fig. 8 The front view of the pressure gradient (ellipse, triangle and square) for air-water two-phase flow through horizontal near wellbore region in three penetration angle cases.

From the above results, we can assume that penetration depth needs to penetrate the damage zone (SZD) for the productivity ratio to be increased, as horizontal well perforation network volume is strongly correlated to production level. However, if the damage zone (SZD) is not penetrated via perforation, the ratio of reservoir permeability to damage zone permeability with regard to well productivity can be especially significant effect. Furthermore, penetration space (perforation density) was shown to have a great effect on the decreasing injection build-up pressure through increasing the penetration space, as illustrated in Fig. 9 (A, D, E and F). This was caused by increases to the mass inflow rate into the wellbore. Note that the optimal penetration density is essential for attaining the best productivity ratio. Ideally, perforation space that is relatively high is preferred for perforated completion in horizontal wells. In this way, the productivity index reduces when the skin zone diameter increases, but increases when both the perforation density and penetration depth rise.

In contrast, the penetration angle has a moderate effect and the perforation diameter quite a low impact. The injection build-up pressure for different penetration angles is reduced when the inflow angle decreases, whereas maximum value is achieved at a penetration angle of $90^{\circ}$, as illustrated in Fig. 9 (D, G and H). From this, it is clear that decreasing the injection build-up pressure while increasing the perforation diameter above $2.5 \mathrm{~cm}$ leads to only a slight drop in pressure as shown in Fig. 9 (C, F, H and L). We can learn the effect of each perforation parameter from these results and, based on the results, choose the design that is optimal. This means choosing the best perforation technique that will lead to a high flow rate, as well as choosing the best density and dimensions for the perforation as a means to accelerate radial inflow. The overall outcome of these informed choices is an increase in the productivity index. 


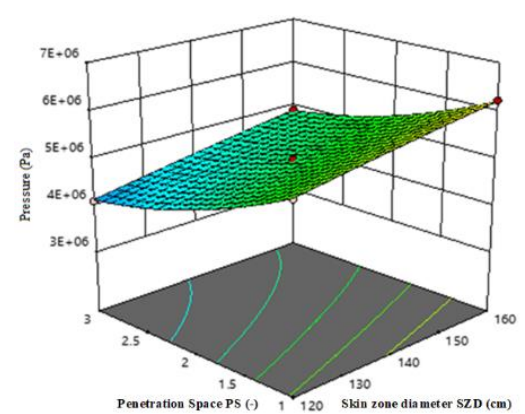

(A)

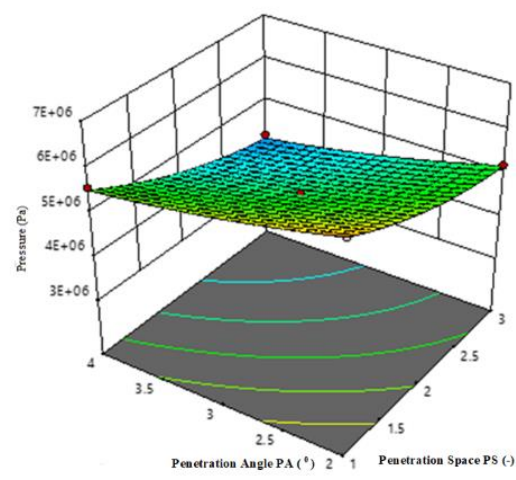

(D)

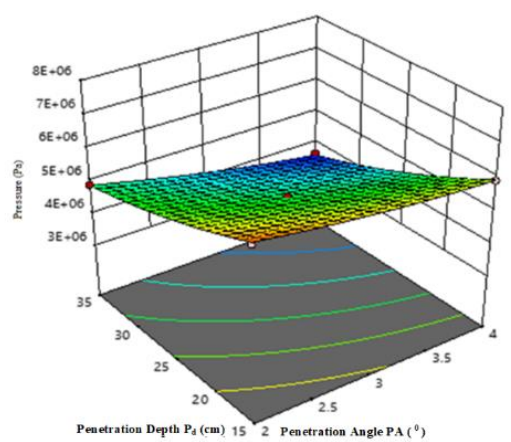

$(\mathrm{G})$

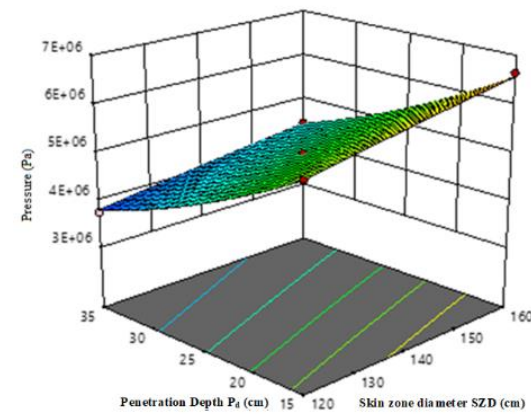

(B)

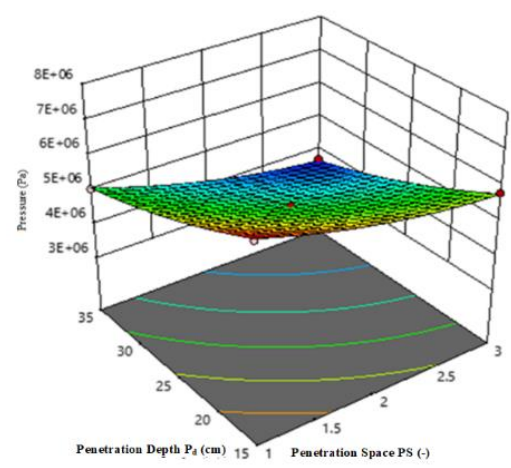

(E)

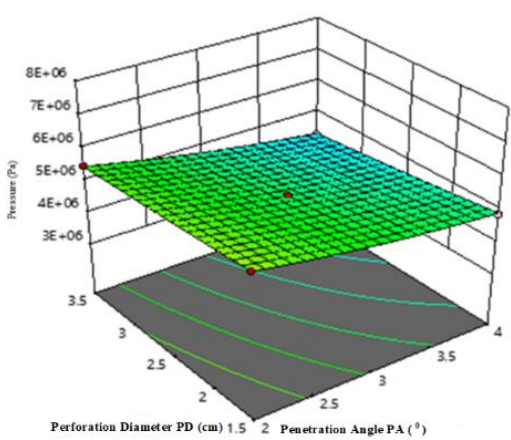

$(\mathrm{H})$

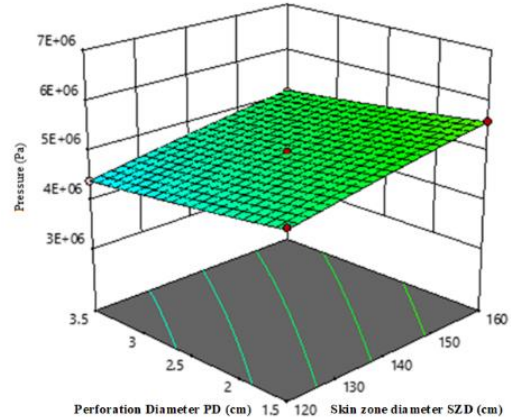

(C)

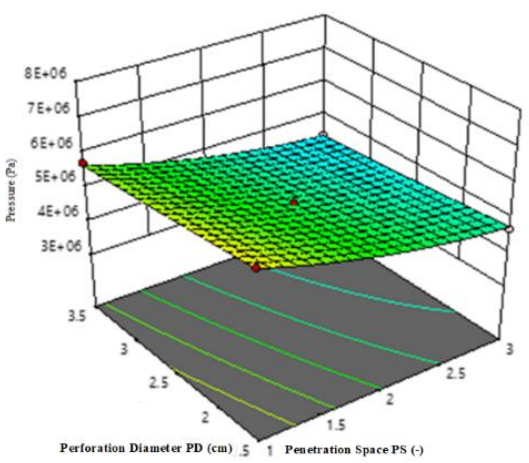

(F)

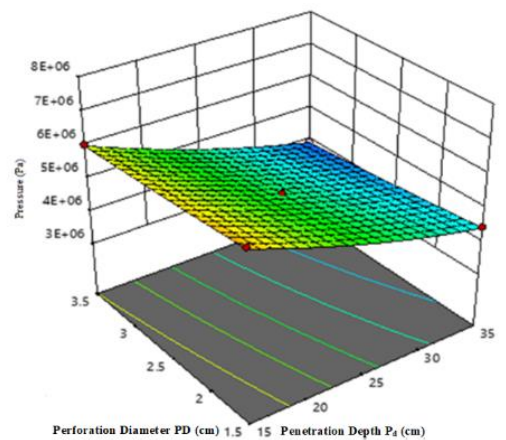

(L)

Fig. 9 The parameters interact with each other and effect on the injection build-up pressure (Pa) in the horizontal near-wellbore region.

Moreover, the results indicate that the skin zone diameter and the penetration depth have a substantial effect on the required time for reaching steady-state conditions, as shown in Fig. 10 (A, B, C, D, E, G and L). This is because, in low permeability formations, it takes a long time for steady-state conditions (i.e., radial flow) to be achieved, particularly in situations involving poor communication with a reservoir and positive skin. Therefore, small damaged region diameter together with high penetration depth, the radial flow increases faster at the damaged near wellbore region, if the perforation size and distribution are optimal. 


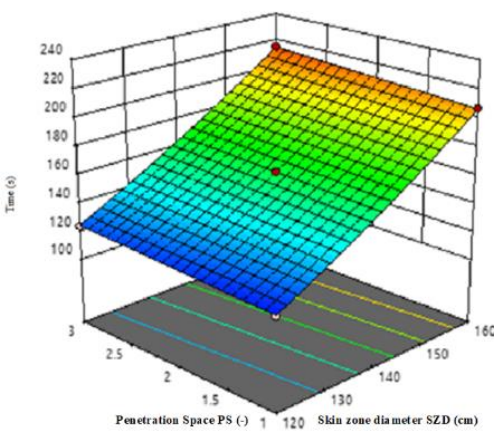

(A)

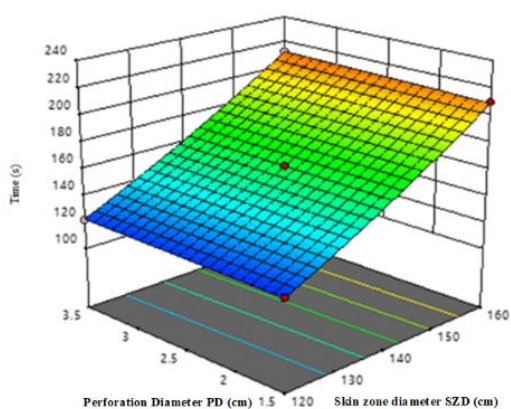

(D)

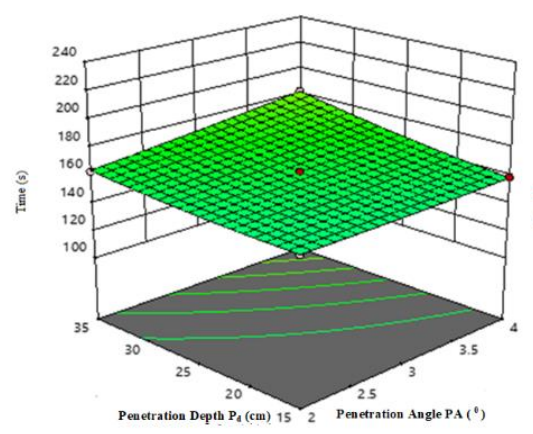

$(\mathrm{G})$

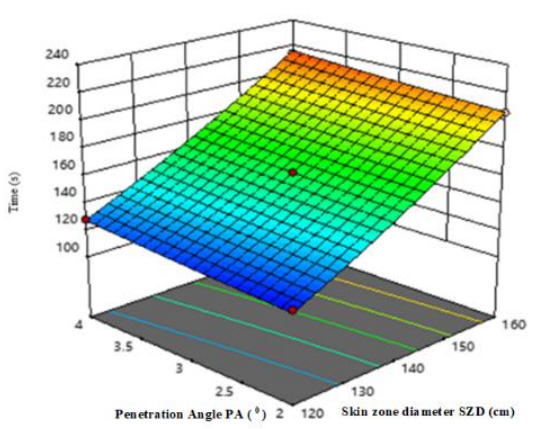

(B)

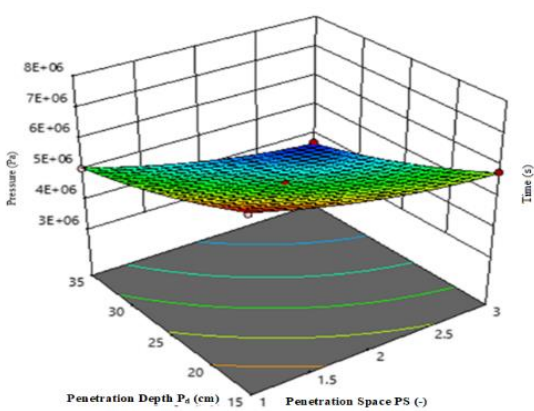

(E)

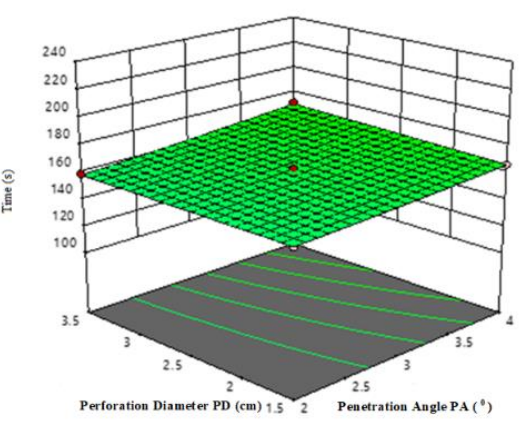

(H)

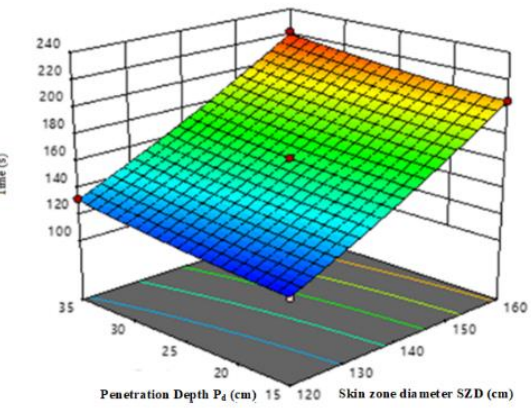

(C)

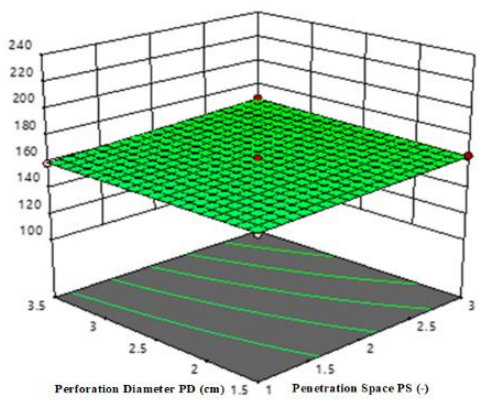

(F)

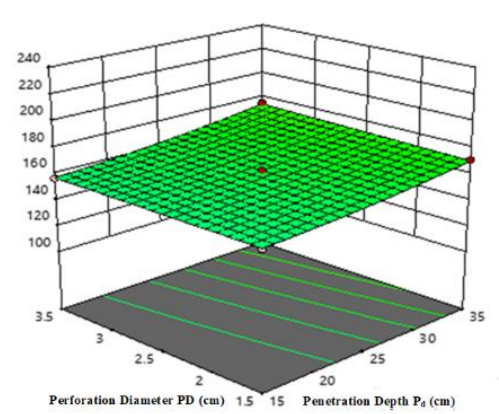

(L)

Fig. 10 The parameters interact with each other and effect on the time required for reaching the steady-state (s) in the horizontal near-wellbore region.

\section{CONCLUSIONS AND FUTURE WORK}

The work has conducted in order to expand the investigation on well completion to choose the optimal perforation dimensions and distribution as well as understanding the multiphase flow behavior in horizontal near wellbore region. Based on the two investigative procedures of numerical and statistical analysis, the following conclusions can be summarized:

1. The numerical and statistical analysis showed a clear view of the effect of each investigated parameter on the injection build-up pressure and time required for reaching the steady-state flow condition.

a. The results showed that skin zone diameter, the penetration depth and the penetration space have a significate effect on the injection build-up pressure, in contrast, the penetration angle has a moderate effect while the perforation diameter has a low impact. 
b. The results indicated the skin zone diameter and the penetration depth have a substantial effect on the required time for reaching the steady-state conditions.

2. Two correlations have been produced from the statistical analysis and numerical simulation that can be used to predict the injection build-up pressure and the required time to reach steady state flow condition for different dimensions and distributions of the perforation at the same flow boundary conditions.

The future work will study the effect of varying near wellbore damage on the multiphase flow behavior.

\section{NOMENCLATURE}

$\begin{array}{llllll}\gamma & \text { porosity } & (\%) & \mathrm{P} & \text { pressure } & (\mathrm{Pa}) \\ \rho_{q} & \text { phase density } & \left(\mathrm{kg} / \mathrm{m}^{3}\right) & \mathrm{t} & \text { time } & (\mathrm{s}) \\ \mu_{q} & \text { phase viscosity } & (\mathrm{Pa} \mathrm{s}) & \mathrm{SZD} & \text { Skin zone diameter } & (\mathrm{cm}) \\ \alpha_{q} & \text { volume fraction } & (\%) & \mathrm{PS} & \text { Penetration Space } & (-) \\ \vec{v}_{q} & \text { phase velocity vector } & (\mathrm{m} / \mathrm{s}) & \mathrm{PA} & \text { Penetration Angle } & \left({ }^{\circ}\right) \\ S_{\emptyset, q} & \text { source term } & (\mathrm{kg} / \mathrm{m}-\mathrm{s}) & \mathrm{P} & \text { Penetration Depth } & (\mathrm{cm}) \\ \Gamma_{q} & \text { diffusion coefficient } & \left(\mathrm{m}^{2} / \mathrm{s}\right) & \mathrm{PD} & \text { Perforation diameter } & (\mathrm{cm}) \\ p_{c} & \text { capillary pressure for wetting phase } & (\mathrm{Pa}) & a & 23250 / \mathrm{cm} & (-) \\ \overline{\bar{\tau}}_{q} & \text { phase shear stress } & (\mathrm{Pa}) & b & 183.75 / \mathrm{cm} 2 & (-) \\ \vec{B}_{f} & \text { body force } & \left(\mathrm{N} / \mathrm{m}^{3}\right) & \mathrm{c} & 0.122917 / \mathrm{cm} & (-) \\ C_{2} & \text { inertial resistance factor } & \left(\mathrm{m}^{-1}\right) & \mathrm{d} & 0.012500 / \mathrm{cm} 2 & (-) \\ \dot{m}_{p q} & \text { mass transfers form phase } p \text { to phase } & (\mathrm{kg} / \mathrm{s}) & & & \\ \dot{m}_{q p} & \text { mass transfers form phase } q \text { to phase } p & (\mathrm{~kg} / \mathrm{s}) & & & \\ K & \text { absolute permeability } & (\mathrm{Darcy}) & & & \\ K_{r, q} & \text { relative permeability } & (\mathrm{Darcy}) & & & \\ \vec{F}_{p q}^{D} & \text { drag force for non-porous flows/region } & (\mathrm{Newton}) & & & \\ \vec{F}_{p q}^{T D} & \text { turbulent dispersed force } & (\mathrm{Newton}) & & & \\ \vec{v}_{p q} \text { and } \vec{v}_{q p} & \text { relative velocity vectors } & (\mathrm{m} / \mathrm{s}) & & & \end{array}$

\section{REFERENCES}

[1] Landman, M. J. and Goldthorpe, W. H., "Optimization of perforation distribution for horizontal wells," Soc. Pet. Eng. - SPE Asia-Pacific Conf. APC 1991, pp. 567-576, 1991.

[2] Asheim, H., Kolnes, J and Oudeman, P., “A flow resistance correlation for completed wellbore” vol. 8, pp. 97-104, 1992.

[3] S. Locke, "Advanced Method for Predicting the Productivity Ratio of a Perforated Well.," JPT, J. Pet. Technol., vol. 33, no. 12, pp. 2481-2488, 1981.

[4] Su, Z and Gudmundsson, J. S., "Pressure drop in perforated pipes: experiments and analysis," SPE - Asia Pacific Oil Gas 
Conf., pp. 563-574, 1994.

[5] Schulkes, R. M. S. M and Utvik, O. H., "Pressure Drop in a Perforated Pipe with Radial Inflow: Single-Phase Flow," SPE J., vol. 3, no. 1, pp. 77-85, 1998.

[6] Li, H., Lu, Y., Peng, X., Lv, X. and Wang, L., "Pressure drop calculation models of wellbore fluid in perforated completion horizontal wells," Int. J. Heat Technol., vol. 34, no. 1, pp. 65-72, 2016.

[7] Rahman, M.A., Heidrick, T. Fleck, B.A., Koksal, M., "Enhancement of the Completion Efficiency of Perforation Tunnels in Petroleum Wells.” ASME Joint US-European Fluids Engineering Summer Meeting, Miami, Florida, USA, FEDSM0698563, July 17-20 (2006).

[8] Rahman, M. A., Mustafiz, S., Biazar, J., Koksal, M. \& Islam, M. R., "Investigation of a novel perforation technique in petroleum wells-perforation by drilling.” J. Frank lin Inst. 344, 777-789 (2007a).

[9] Rahman, M. A., Mustafiz, S., Koksal, M. \& Islam, M. R., "Quantifying the skin factor for estimating the completion efficiency of perforation tunnels in petroleum wells.” J. Pet. Sci. Eng. 58, 99-110 (2007b).

[10] Rahman, M.A. "Scale-up of Perforation Process from Laboratory Model to Bottom-hole Dimensions." Journal of Porous Media. 11(1),19-34 (2008).

[11] Yildiz, T., "Productivity of Selectively Perforated Vertical Wells," Proc. Int. Oil Gas Conf. Exhib. China, IOGCEC, no. February, pp. 821-831, 2000.

[12] Ansah, J., Proett, M. A., and Soliman, M. Y., "Advances in Well Completion Design: A New 3D Finite-Element Wellbore Inflow Model for Optimizing Performance of Perforated Completions," Proc. - SPE Int. Symp. Form. Damage Control, no. 2, pp. 585-595, 2002.

[13] Dogulu, Y. S., "Modeling of well productivity in perforated completions," Proc. - SPE Annu. West. Reg. Meet., pp. 109$118,1998$.

[14] Hagoort, J., “An analytical model for predicting the productivity of perforated wells," J. Pet. Sci. Eng., vol. 56, no. 4, pp. 199-218, 2007.

[15] Zheng, L., Rahman, M. A., Ahammad, M. J., Butt, S. D. \& Alam, J. M. "Experimental and numerical investigation of a novel technique for perforation in petroleum reservoir.” Proc. - SPE Int. Symp. Form. Damage Control 2016-January, (2016).

[16] Ahammad, M. J., Rahman, M. A., Zheng, L., Alam, J. M. \& Butt, S. D. "Numerical investigation of two-phase fluid flow in a perforation tunnel.” J. Nat. Gas Sci. Eng. 55, 606-611 (2018).

[17] Zeboudj, F., Division, P., Amenas, I., and Bahi, L., "Horizontal Well Performance Flow Simulation CFD-Application" Spe Prod. Oper., no. June, pp. 8-10, 2010.

[18] Dankwa, OK., Igbokoyi AO., "Effects of Partial Completion on Productivity Index," no. August, pp. 6-8, 2012.

[19] ANSYS Inc. FLUENT® 18.1 User's Guide. 2016 (Section 7.2.3). 